\title{
High-level expression of stem cell marker CD133 in clear cell renal cell carcinoma with favorable prognosis
}

\author{
KYUNGEUN KIM ${ }^{1}$, HYOJIN IHM ${ }^{2}$, JAE Y. RO ${ }^{2}$ and YONG MEE CHO ${ }^{2}$ \\ ${ }^{1}$ Department of Pathology, Kangbuk Samsung Hospital, Sungkyunkwan University School of Medicine; \\ ${ }^{2}$ Department of Pathology, University of Ulsan College of Medicine, Asan Medical Center, Seoul, Republic of Korea
}

Received March 21, 2011; Accepted July 22, 2011

DOI: $10.3892 / \mathrm{ol} .2011 .368$

\begin{abstract}
The cancer stem cell (CSC) model suggests that high levels of CSCs within a tumor are associated with poor prognosis. The aim of this study was to investigate the expression of the stem cell marker CD133 in clear cell renal cell carcinoma (ccRCC), and its prognostic significance. The expression of CD133 was examined in 140 cases of ccRCC using immunohistochemistry. Ki-67 and Oct-4 were doubleimmunostained with CD133 to evaluate the proliferative activity and the stemness of CD133-expressing cells, respectively. CD133 expression was observed in 45 cases $(32.1 \%)$ and high levels of expression were found to be associated with a macro-/microcystic pattern, non-sarcomatoid changes and non-metastatic disease. The Ki-67 labeling index tended to be lower in CD133-expressing ccRCCs compared to nonexpressing tumors. CD133-expressing tumor cells rarely expressed Oct-4. A high degree of CD133 expression was observed in ccRCC with more differentiated morphology and non-metastatic disease, suggesting that CD133 is a favorable prognostic marker. These results also indicate that CD133 as a single marker may not be sufficient for CSC identification in ccRCC and, therefore, more specific CSC markers should be developed.
\end{abstract}

\section{Introduction}

Renal cell carcinoma (RCC) is the most common malignant neoplasm of the kidney, accounting for $5 \%$ of all malignancies in the USA (1). RCC is one of the most lethal genitourinary malignancies, exhibiting a $67 \%$ 5-year survival rate (1). Kidneyconfined RCC, however, has a relatively favorable prognosis with a 70-90\% 5-year survival rate, whereas advanced disease with systemic metastasis results in a poorer prognosis with a

Correspondence to: Dr Yong Mee Cho, Department of Pathology, Asan Medical Center, University of Ulsan College of Medicine, 388-1 Pungnap-2dong, Songpa-gu, Seoul 138-736, Republic of Korea E-mail: yongcho@amc.seoul.kr

Key words: clear cell renal cell carcinoma, CD133, Ki-67, Oct-4, metastasis
0-10\% 5-year survival rate (2). As systemic metastasis usually occurs 3.5-4 asymptomatic years after curative surgery, the precise prediction of RCC prognosis either preoperatively or in the immediate postoperative period may aid in the selection of the optimal postoperative treatment modality (3). The tumor stage and grade are the most widely accepted prognostic factors (4); however, an integrative approach that combines various clinicopathological and molecular prognostic factors appears to improve predictive accuracy (5).

According to the cancer stem cell (CSC) model, tumor cells are heterogeneous. Typically, a small population of tumor cells, termed CSCs, are capable of initiating tumor development due to their self-renewal capacity, which gives rise to more CSCs and multipotency, generating the bulk of advanced differentiated tumor cells (6-8). Disseminated CSCs may induce metastatic disease and high levels of CSCs within a tumor, resulting in a poor patient outcome (9). However, the proportion of CSCs and their prognostic significance have yet to be defined in malignant tumors of the kidney.

The pentaspan membrane glycoprotein CD133 (Prominin-1), initially identified as a cell surface antigen specific to hematopoietic stem cells, has been used as a stem cell marker in various normal and neoplastic human tissues, including the brain, skin, prostate, pancreas and kidney $(10,11)$. Recent studies have identified CD133 expression as a poor prognostic factor, particularly in colorectal cancer patients (12-14). In the normal kidney, it has been well established that CD133-positive $\left(\mathrm{CD} 133^{+}\right)$cells exhibit stem cell characteristics, including self-renewal, multipotency and involvement in renal repair (15). By contrast, the expression of CD133 in malignant kidney disease requires further clarification. In this regard, only one previous study described the expression of CD133 in RCC. CD133 expression was shown in two out of three cases of clear cell renal cell carcinoma (ccRCC), the most common malignant neoplasm of the kidney, which accounts for approximately $83 \%$ of RCC cases $(16,17)$.

Oct-4 (also known as OCT3 and POU5F1) is a POU-domain octamer-binding transcription factor (18). Typically, Oct-4 expression is confined to the pluripotent cells of embryo and embryonic stem cells (ESCs). Oct-4 acts as a key regulator for the self-renewal of normal stem cells and the maintenance of pluripotency in ESCs. The aberrant expression of Oct- 4 in pluripotent cells results in the initiation of differentiation and the progressive loss of potency (18-20). 
In the present study, in an attempt to define the prognostic significance of CD133 expression in ccRCC, we evaluated its expression in 140 cases and examined the relationship between these findings and clinicopathological prognostic factors. The proliferative activity and stemness of CD133-expressing cells was evaluated by double immunohistochemical staining with Ki-67 and Oct-4, respectively.

\section{Materials and methods}

Patients and pathological examination. This study was approved by the Asan Medical Center Institutional Review Board. We reviewed the pathological materials of 167 RCC patients treated by surgical tumor removal during the year 2005 at the Asan Medical Center, Seoul, Republic of Korea. Histological slides from all patients were examined for the diagnostic reassessment of tumor type according to the 2004 World Health Organization tumor classification and the Fuhrman nuclear grading system $(4,21)$. A total of 27 patients with non-ccRCC tumors (chromophobe, 10; unclassified, 8; papillary, 7; and multilocular cystic, 2) were excluded. In total, 140 patients with ccRCC were selected for this retrospective study. During the slide review, the proportion of macro- and microcystic patterns, sarcomatoid region and necrosis were recorded for each tumor. The clinical information was obtained through a review of the patient medical records and radiological findings. Tumors were staged according to the 2002 Tumor Node Metastasis (TNM) staging system proposed by the American Joint Committee on Cancer (22).

Immunohistochemistry. Representative formalin-fixed and paraffin-embedded tumor sections were immunostained using antibodies against CD133 [CD133/1 (AC133); 1:50 dilution; Miltenyi Biotec, Auburn, CA, USA] and Ki-67 (1:100 dilution; Thermo Scientific, Fremont, CA, USA) or Oct-4 (OCT3/4, C-10, 1:200 dilution; Santa Cruz Biotechnology, Santa Cruz, CA, USA). Double immunostaining was feasible, as CD133 exhibits distinct cell membrane expression, and both $\mathrm{Ki}-67$ and Oct-4 are expressed in the nucleus. Immunohistochemical staining was performed as previously described, with minor modifications (23). Endogenous peroxidase activity and non-specific binding of antibodies were blocked using hydrogen peroxide and an Ultra-V block kit (LabVision, Fremont, CA, USA). Antigen retrieval was achieved by steaming the samples in $10 \mathrm{mM}$ citrate buffer $(\mathrm{pH} 6.0)$ for $15 \mathrm{~min}$ in a microwave apparatus. For the CD133 and Ki-67 staining, sections were incubated with anti-Ki-67 antibody for $1 \mathrm{~h}$, followed by incubation in anti-CD133 antibody at $4^{\circ} \mathrm{C}$ overnight. The incubation of secondary antibodies and chromogenic detection were performed using the UltraVision LP large-volume detection system (Thermo Scientific). Double staining for CD133 and Oct-4 was performed on 45 cases of CD133-expressing tumors using the Bond Polymer Intense Detection System (Leica Microsystems, Wetzlar, Germany) as previously described (23). The anti-OCT3 antibody was applied for the first $15 \mathrm{~min}$, followed by incubation with anti-CD133 antibody for another $15 \mathrm{~min}$ at room temperature. Sections were then treated with post-primary and polymer reagents. Diaminobenzidine was used, as the chromogen and tissues were counterstained with hematoxylin. Normal human kidney and testicular embryonal
Table I. Clinicopathological characteristics of 140 patients with clear cell renal cell carcinoma.

\begin{tabular}{|c|c|}
\hline Variable & No. of patients (\%) \\
\hline \multicolumn{2}{|c|}{ Age (years) } \\
\hline$\leq 40$ & $18(12.9)$ \\
\hline $41-60$ & $84(60.0)$ \\
\hline$\geq 61$ & $38(27.1)$ \\
\hline \multicolumn{2}{|l|}{ Gender } \\
\hline Male & $100(71.4)$ \\
\hline Female & $40(28.6)$ \\
\hline \multicolumn{2}{|c|}{ Nephrectomy } \\
\hline Radical & $104(74.3)$ \\
\hline Partial & $36(25.7)$ \\
\hline \multicolumn{2}{|c|}{ Laterality } \\
\hline Right & $69(49.3)$ \\
\hline Left & $71(50.7)$ \\
\hline \multicolumn{2}{|c|}{ Tumor size $(\mathrm{cm})$} \\
\hline$\leq 4.0$ & $72(51.4)$ \\
\hline $4.1-7.0$ & $47(33.6)$ \\
\hline$>7.0$ & $21(15.0)$ \\
\hline \multicolumn{2}{|c|}{ Fuhrman grade } \\
\hline 1 & $4(2.9)$ \\
\hline 2 & $53(37.9)$ \\
\hline 3 & $51(36.4)$ \\
\hline 4 & $32(22.8)$ \\
\hline \multicolumn{2}{|l|}{ T stage } \\
\hline 1 & $104(74.3)$ \\
\hline 2 & $8(5.7)$ \\
\hline 3 & $28(20.0)$ \\
\hline \multicolumn{2}{|l|}{$\mathrm{N}$ stage } \\
\hline $\mathrm{X}$ & 90 \\
\hline 0 & $47(94.0)$ \\
\hline 1 & $1(2.0)$ \\
\hline 2 & $2(4.0)$ \\
\hline \multicolumn{2}{|l|}{ M stage } \\
\hline $\mathrm{X}$ & 0 \\
\hline 0 & $116(82.9)$ \\
\hline 1 & $24(17.1)$ \\
\hline
\end{tabular}

carcinomas were used as positive controls for CD133 and Oct-4, respectively. Negative controls omitting primary antibodies were included.

During the microscopic examination of the immunostained slides, the sub-cellular localization of CD133 in tumor cells was recorded and the percentage of $\mathrm{CD}_{133}{ }^{+}$cells was measured by manual counting. Even a low percentage of $\mathrm{CD}_{133^{+}}$tumor cells were regarded as CD133-expressing tumors since CSCs usually constitute only a small proportion of cancer cells, although the frequency differs with the tumor type and cell assay methods employed $(7,8,24)$. The Ki-67 labeling index was measured by calculating the mean percentage of $\mathrm{Ki}-67^{+}$ cells in three representative fields at a high magnification 


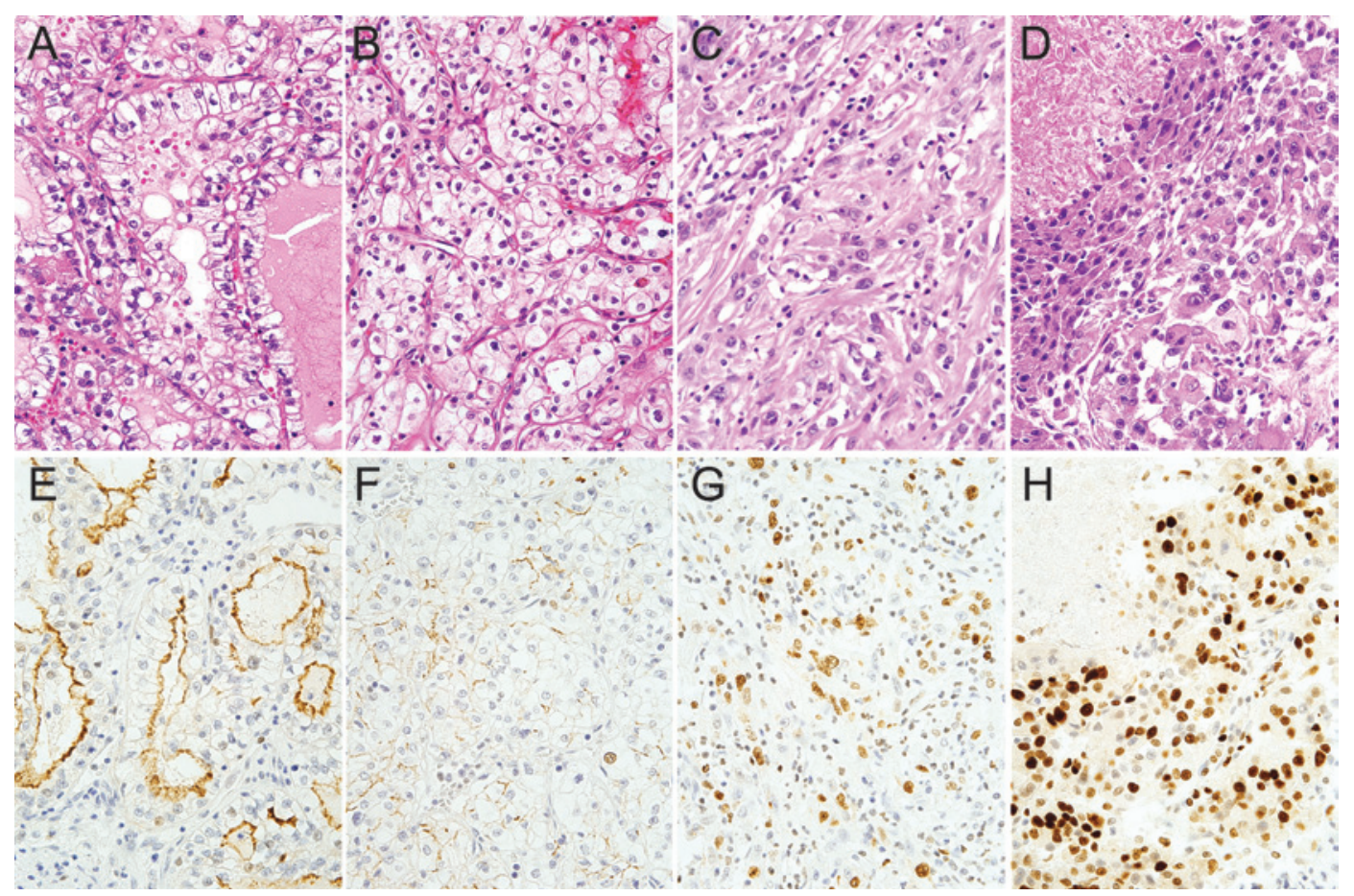

Figure 1. Correlation of histological features of clear cell renal cell carcinoma (ccRCC) with the expression of (A-D) CD133 and (E-H) Ki-67. Double immunohistochemical staining for CD133 and Ki-67 shows the CD133 expression in the apical/apicolateral cell membrane of tumor cells and Ki-67 in the nuclei. ccRCC shows (A and E) strong CD133 expression in the microcystic regions, (B and F) weak expression in the alveolar region and no expression in the $(\mathrm{C}$ and $\mathrm{G})$ sarcomatoid and (D and $\mathrm{H}$ ) necrotic regions. By contrast, Ki-67 nuclear expression is low in (E) microcystic and (F) alveolar regions, but high in (G) sarcomatoid and $(\mathrm{H})$ necrotic regions (original magnification, $\mathrm{x} 400$ ).

(x400). Strong nuclear staining was regarded as positive for Oct-4 expression. Oct-4 expression was analyzed in 40 cases of CD133-expressing ccRCC, as 5 of the tissue samples were lost during immunohistochemical staining.

Statistical analysis. Data were analyzed using the SPSS 12.0K software (SPSS, Inc., Chicago, IL, USA). Crosstabs, the Pearson's Chi-square, Fisher's exact, and the Kruskal-Wallis tests, as well as a calculation of Pearson's correlation coefficient were used as appropriate. The Cox's proportional hazard model was employed in a multivariate analysis. $\mathrm{P}<0.05$ was regarded as statistically significant.

\section{Results}

Clinicopathological characteristics. The clinicopathological characteristics of the 140 ccRCC cases are shown in Table I. The ages ranged from 21 to 80 years (median 54), with a male-to-female ratio of 2.5:1. Seven cases had previously undergone contralateral nephrectomy due to RCC. Among the 7 cases, 1 case with cerebellar hemangioblastoma was diagnosed as von Hippel-Lindau disease. The mean tumor size was $4.7 \mathrm{~cm}$ in the grexatest dimension (range 0.6-17 cm). Most tumors (112 cases, $80 \%$ ) were confined to the kidney. The remaining 28 cases revealed direct invasion to the perinephric fat tissue (24 cases) and/or gross extension into the renal vein (15 cases). Regional lymph node dissection was performed in 50 cases and lymph node metastasis was identified in 3 cases. Distant metastasis was present in 24 cases; as single-organ metastasis in 16 and as multi-organ metastases in 8 cases. Fifteen cases presented with metastatic disease at the time of initial diagnosis, and metastasis developed during the postoperative follow-up period in the remaining 9 cases. The most common metastatic site was the lung (19 cases), followed by bone ( 4 cases), liver ( 3 cases), brain ( 2 cases), supraclavicular lymph node (1 case), stomach (1 case), soft tissue (1 case) and adrenal gland (1 case). During the median follow-up period of 43.6 months (range 3.7-54.6), 13 patients succumbed and in 4 cases this was due to ccRCC.

Microscopically, the majority of the cases (104 cases, $74.3 \%$ ) were Fuhrman nuclear grade 2 or 3 . The tumors revealed the characteristic histological features of ccRCC: alveolar and/or acinar arrangements of tumor cells with a well-developed network of thin-walled blood vessels and clear to eosinophilic cytoplasm (Fig. 1A). A macro- or microcystic pattern of dilated alveolar and acinar structures was noted in 101 patients $(72.1 \%)$ with a wide range of the pattern (1-100\%; mean 42\%). The two poor prognostic histological features, tumor necrosis and sarcomatoid changes, were found in $25(17.9 \%)$ and 6 cases (4.3\%), respectively. The necrotic region ranged from 1 to $80 \%$ of tumors (mean $24.7 \%$ ). The sarcomatoid region constituted $5-90 \%$ (mean $40.8 \%$ ) of the tumor sections examined. The mean Ki-67 labeling index of the 140 cases was $18 \%$, with a range from 1 to $90 \%$.

CD133 expression in ccRCC with favorable clinicopathological characteristics. CD133 expression was present in 45 cases (32.1\%), with a wide range of expression (1-100\%; mean $36.9 \%$ ). CD133 was significantly expressed in the apical or apicolateral membrane of tumor cells in the macro-/microcystic region (Fig. 1A and E). The macrocystic region showed a greater CD133 intensity than the microcystic region (data 
not shown). In the alveolar pattern where the luminal space was indistinct, CD133 was expressed at the cell membrane of tumor cells with a weaker intensity compared to that in macro-/microcystic regions (Fig. $1 \mathrm{~B}$ and F). The CD133 expression revealed a positive correlation with the proportion of the macro-/microcystic region $(\mathrm{p}<0.001)$.

The relationship between CD133 expression and the clinicopathological prognostic factors are shown in Table II. The high-level expression of CD133 was more prevalent in males compared to females ( $\mathrm{p}=0.001)$. The kidney-confined ccRCC revealed a tendency to express more CD133 than locally advanced cases $(\mathrm{p}=0.057)$. Furthermore, non-metastatic ccRCC revealed higher CD133 expression levels than cases with distant metastasis $(\mathrm{p}=0.047)$, although this correlation was not significant in the multivariate analysis with regard to stage and Fuhrman grade. CD133 expression in ccRCC showed a negative correlation with the proportion of sarcomatoid change $(\mathrm{p}<0.001)$. In ccRCCs containing sarcomatoid change, CD133 expression was not identified in the sarcomatoid region, and only rare $\mathrm{CD} 133^{+}$tumor cells were present in non-sarcomatoid regions (Fig. $1 \mathrm{C}$ and $\mathrm{G}$ ). ccRCC cases with accompanying necrosis tended to express lower levels of CD133 than those without necrosis ( $p=0.081$ ) (Fig. 1D and H). ccRCCs with a significant tumor necrosis occupying $>10 \%$ of the tumor volume were observed in 18 cases, and 14 of these (77.8\%) did not express CD133 in the tumor. The remaining 4 cases showed a low expression of CD133 (3-20\%) in the viable tumor, with no increased expression in the perinecrotic region. No significant correlation was evident between the CD133 expression levels and the Fuhrman grade, tumor size or nodal metastasis status (Table II).

Although the disease-related survival did not show any significant correlation with CD133 expression due to a short follow-up period, an analysis of the 4 cases that resulted in death from ccRCC was performed. These 4 cases were characterized by a lack of CD133 expression, Fuhrman grade 4 , a small amount of macro-/microcystic region (5-25\%), lung metastasis and tumor necrosis. Tumor extension into perinephric fat tissue and lymphatic invasion were also noted in 3 of the 4 patients.

Low proliferative activity of CD133-expressing ccRCC. The Ki-67 labeling index was higher in ccRCCs that did not express CD133 (mean 19.5\%) than in those that did (mean $14.7 \%$ ), although this difference was not statistically significant $(\mathrm{p}=0.097)$. CD133 ${ }^{+}$tumor cells lining the macrocystic spaces rarely expressed $\mathrm{Ki}-67$, whereas sarcomatoid and perinecrotic regions, where the CD133 expression was low or absent, revealed high expression levels of Ki-67 (Fig. 1A-H). The Ki-67 labeling index of $\mathrm{CD}_{133^{+}}$tumor cells was examined in 45 cases of CD133-expressing ccRCC to measure the proliferative activity of $\mathrm{CD}_{133^{+}}$cells. The mean Ki-67 labeling index of $\mathrm{CD}_{133}{ }^{+}$cells was $7.7 \%$, which was lower than that of the average Ki-67 labeling index of all 140 ccRCC cases (18\%) and of 95 cases of CD133 non-expressing ccRCCs (19.5\%).

Low expression of Oct-4 in CD133+ tumor cells in CD133expressing $c c R C C$. Oct-4 expression was investigated in CD133-expressing tumors to examine the stemness of CD133+ cells. Being a transcription factor, Oct- 4 was expressed in the
Table II. Correlation between CD133 expression and clinicopathological features in 140 patients with clear cell renal cell carcinoma.

\begin{tabular}{cc}
\hline Variable & $\begin{array}{c}\text { Mean percentage of } \\
\text { CD133 expression }\end{array}$
\end{tabular}

Gender

Male

16.4

Female

0.5

Fuhrman grade

1 and 2

9.6

3 and 4

Tumor size $(\mathrm{cm})$

$\leq 4.0$

4.1-7.0

9.6

$>7.0$

T stage

$\mathrm{T} 1$ and $\mathrm{T} 2$

12.4

$\mathrm{T} 3$ and $\mathrm{T} 4$

9.8

LN metastasis

Absent

Present

Distant metastasis

Absent

Present

Necrosis

Absent

Present

Sarcomatoid component

$\begin{array}{lr}\text { Absent } & 12.4 \\ \text { Present } & 0.5\end{array}$

0.5

0.057

LN, lymph node. Regional lymph node dissection was performed in 50 cases.

nucleus, as expected (Fig. 2A-C). CD133+ tumor cells rarely expressed Oct-4 (Fig. 2B), whereas significant Oct-4 expression was observed in CD133- tumor cells (Fig. 2C).

\section{Discussion}

In the present study, CD133 expression was increased in non-metastatic ccRCC and in those without a sarcomatoid component. CD133-expressing ccRCC exhibited a lack of necrosis and low proliferative activity.

The high expression of CD133 in ccRCC with favorable clinicopathological characteristics was an unexpected result, as CD133 has been applied as a putative CSC marker in numerous malignant tumors, and its high expression has been considered a poor prognostic factor. CD133 is currently applied as a cell-surface marker to isolate CSCs in malignant tumors of the colon, brain, lung, prostate, pancreas, liver, stomach and uterus $(11,25-27)$. A CD133+ ${ }^{+}$sub-population in colon cancer was highly enriched with CSCs that were 

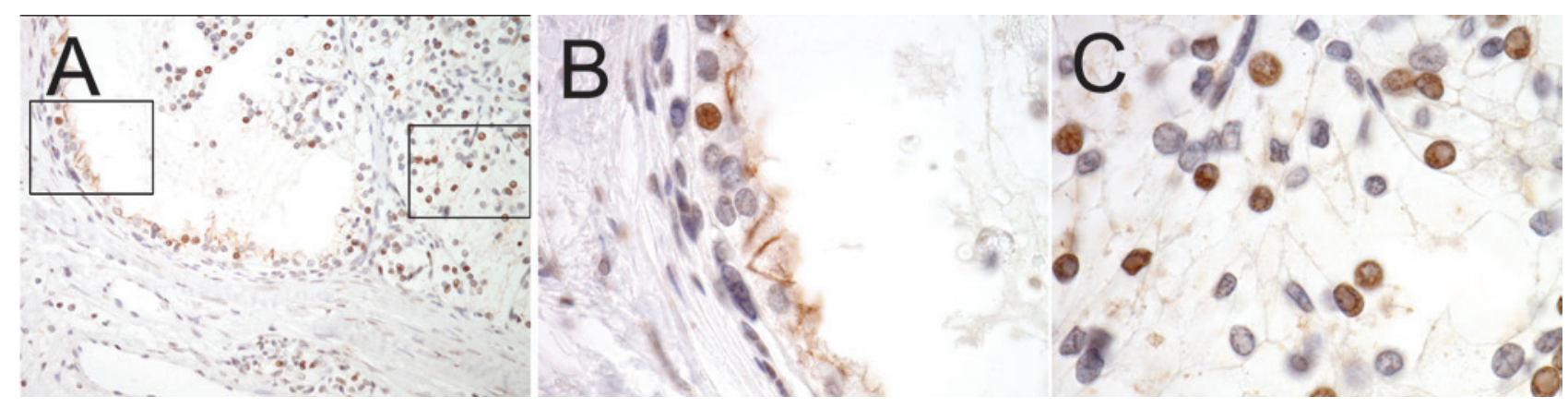

Figure 2. Low expression levels of Oct-4 in CD133+ tumor cells in CD133-expressing clear cell renal cell carcinoma. Double immunohistochemical staining for CD133 and Oct-4 demonstrates CD133 expression at the apical/apicolateral cell membrane of tumor cells and Oct-4 in the nuclei. CD133-negative solid areas (right inset) show higher Oct-4 expression than do CD133-positive microcystic areas (left inset) (A). The microcystic and solid areas in (A) are magnified in (B) and (C), respectively (original magnification: A, x400; B and C, x1,000).

capable of forming tumors in serial xenotransplantation (selfrenewal) and reproducing the heterogeneous morphological and antigenic patterns of the original tumor (multipotency) $(28,29)$. Previous studies have shown that CSC has poor prognostic significance and therapeutic relevance. The proportion of $\mathrm{CD}_{133^{+}}$cells in the glioma of the brain was an independent risk factor for tumor regrowth and was thus negatively correlated with progression-free and overall survival (30). In colon cancer, high levels of CD133 expression were associated with a shorter relapse-free interval and poor overall survival (31). Furthermore, CSCs appear to be highly resistant to chemoradiation therapy (26,32-34). In an atypical teratoid/rhabdoid tumor of the brain, high levels of $\mathrm{CD}_{133^{+}}$cells were positively correlated with radioresistance (35). A high-level expression of CD133 in residual colon cancer tissue following radiation therapy predicted poor disease-free and overall survival rates (13). These findings suggest that the estimation of the CSC proportion within a tumor has clinical relevance for CSC-targeted therapy. In addition, these studies indicate that successful tumor control requires the eradication of CSCs during cancer treatment. This issue has been actively studied to develop targeted therapy for CSCs. For example, an anti-CD133 antibodydrug complex has been shown to conjugate effectively and inhibit the growth of the Hep3B hepatocellular carcinoma cell line in vitro and in vivo (36).

However, it appears that CD133 expression does not predict poor prognosis for every tumor type. In ovarian cancer and malignant melanoma patients, no differences were observed in the overall survival between tumors with negative CD133 and those expressing the marker $(37,38)$. In the present study, CD133 expression was increased in ccRCC patients showing favorable clinicopathological characteristics, although disease-related survival was not significantly correlated with CD133 levels, mainly due to a short follow-up period. The indolent nature of $\mathrm{CD} 133^{+} \mathrm{RCC}$ cells is supported by previous studies demonstrating that $\mathrm{CD} 133^{+}$cells isolated from human RCCs were incapable of forming tumors when transplanted independently into severe combined immunodeficiency (SCID) mice, although these cells significantly increased tumor development and growth when co-transplanted with RCC cells (39). Taken together, these data indicate that $\mathrm{CD} 133$ expression levels may vary with regard to prognostic significance depending on the tumor type.
In contrast to the widely held theory that CSCs are relatively undifferentiated, our results demonstrate that CD133 is highly expressed in the more differentiated macro-/microcystic region of ccRCCs with a low expression of Oct- 4 in CD133+ tumor cells, whereas CD133 expression was absent in the dedifferentiated sarcomatoid region. CD133 expression was found to be reduced in those regions with an alveolar growth pattern, where the luminal structure was inconspicuous. The high expression of CD133 in the macro-/microcystic tumor structures and the favorable prognosis for ccRCC may be explained in three ways. First, CD133 is a cell membrane protein that is usually expressed in plasma membrane protrusions, including microvilli (40-44). Given that microvilli are abundant in differentiated cells, including the proximal tubules of the adult kidney, this may explain the absent or low expression levels of CD133 in the undifferentiated sarcomatoid region and less differentiated alveolar regions. However, this observation does not fully explain the high expression levels of CD133 in the macro-/microcystic regions of ccRCC since not all these regions expressed the marker, and a small number of cells in the proximal tubules expressed CD133 in normal kidney tissue remote from the tumor. Second, since CD133 is a glycoprotein, its expression may reflect aberrant glycosylation or a variation in glycosylation status according to the degree of tumor differentiation. It has been well established that the glycosylation of CD133 varies with cellular differentiation and malignant transformation, and the anti-CD133 antibody used in this study identifies only the undefined glycosylated epitopes $(10,16,40)$. Finally, $\mathrm{CD} 133^{+}$cells may represent a heterogeneous population of tumor cells that contains a small number of CSCs and a large number of differentiated non-CSC cells. Our immunohistochemical staining for CD133 and Oct-4 supports this hypothesis, as the majority of $\mathrm{CD} 133^{+}$cells did not express Oct-4, although a small number of cells co-expressed CD133 and Oct-4. Taken together, these data suggest that the proportion of CD133-expressing cells in ccRCC identified through immunohistochemical staining may not accurately reflect the overall proportion of CSCs. Therefore, CD133 as a single marker is not sufficient for CSC identification in ccRCC, and other, more specific CSC markers need to be developed.

In the present study, the ccRCCs from male patients revealed higher CD133 expression levels than those from female patients. Although the impact of gender on stem cell populations should be defined, previous studies have shown 
that the number of circulating $\mathrm{CD} 133^{+}$endothelial progenitor cells is higher in pre-menopausal females compared to postmenopausal ones and age-matched males $(45,46)$. Therefore, the gender difference in CD133 expression in ccRCC and its clinical significance require further clarification.

\section{Acknowledgements}

This study was supported by a grant (no. 2008-388) from the Asan Institute for Life Sciences, Seoul, Republic of Korea.

\section{References}

1. Jemal A, Siegel R, Ward E, Hao Y, Xu J and Thun MJ: Cancer statistics. CA Cancer J Clin 59: 225-249, 2009.

2. Wein AJ, Kavoussi LR, Novick AC, Partin AW and Peters CA: Campbell-Walsh Urology. 9th edition. Saunders Elsevier, Philadelphia, 2007.

3. Levy DA, Slaton JW, Swanson DA and Dinney CP: Stage specific guidelines for surveillance after radical nephrectomy for local renal cell carcinoma. J Urol 159: 1163-1167, 1998

4. Eble JN, Epstein JI and Sesterhenn IA: World Health Organization classification of tumors. IARC Press, Lyon, 2004.

5. Kim HL, Seligson D, Liu X, et al: Using protein expressions to predict survival in clear cell renal carcinoma. Clin Cancer Res 10: 5464-5471, 2004.

6. Reya T, Morrison SJ, Clarke MF and Weissman IL: Stem cells, cancer, and cancer stem cells. Nature 414: 105-111, 2001.

7. Clarke MF, Dick JE, Dirks PB, et al: Cancer stem cells - perspectives on current status and future directions: AACR Workshop on cancer stem cells. Cancer Res 66: 9339-9344, 2006.

8. Burkert J, Wright NA and Alison MR: Stem cells and cancer: an intimate relationship. J Pathol 209: 287-297, 2006.

9. Brabletz T, Jung A, Spaderna S, Hlubek F and Kirchner T: Opinion: migrating cancer stem cells - an integrated concept of malignant tumour progression. Nat Rev Cancer 5: 744-749, 2005

10. Miraglia S, Godfrey W, Yin AH, et al: A novel fivetransmembrane hematopoietic stem cell antigen: isolation, characterization, and molecular cloning. Blood 90: 5013-5021, 1997.

11. Mizrak D, Brittan M and Alison MR: CD133: molecule of the moment. J Pathol 214: 3-9, 2008.

12. Horst D, Kriegl L, Engel J, Kirchner T and Jung A: Prognostic significance of the cancer stem cell markers CD133, CD44, and CD166 in colorectal cancer. Cancer Invest 27: 844-850, 2009.

13. Wang Q, Chen ZG, Du CZ, Wang HW, Yan L and Gu J: Cancer stem cell marker CD133+ tumour cells and clinical outcome in rectal cancer. Histopathology 55: 284-293, 2009.

14. Kojima M, Ishii G, Atsumi N, Fujii S, Saito N and Ochiai A: Immunohistochemical detection of CD133 expression in colorectal cancer: a clinicopathological study. Cancer Sci 99: 1578-1583, 2008.

15. Bussolati B, Bruno S, Grange C, et al: Isolation of renal progenitor cells from adult human kidney. Am J Pathol 166: 545-555, 2005.

16. Florek M, Haase M, Marzesco AM, et al: Prominin-1/CD133, a neural and hematopoietic stem cell marker, is expressed in adult human differentiated cells and certain types of kidney cancer. Cell Tissue Res 319: 15-26, 2005.

17. Cheville JC, Lohse CM, Zincke H, Weaver AL and Blute ML: Comparisons of outcome and prognostic features among histologic subtypes of renal cell carcinoma. Am J Surg Pathol 27: 612-624, 2003

18. Cheng L, Sung MT, Cossu-Rocca P, et al: OCT4: biological functions and clinical applications as a marker of germ cell neoplasia. J Pathol 211: 1-9, 2007.

19. Jones TD, Ulbright TM, Eble JN and Cheng L: OCT4: a sensitive and specific biomarker for intratubular germ cell neoplasia of the testis. Clin Cancer Res 10: 8544-8547, 2004.

20. Lengner CJ, Welstead GG and Jaenisch R: The pluripotency regulator Oct4: a role in somatic stem cells? Cell Cycle 7: 725-728, 2008

21. Fuhrman SA, Lasky LC and Limas C: Prognostic significance of morphologic parameters in renal cell carcinoma. Am J Surg Pathol 6: 655-663, 1982.
22. Greene FL and Fleming ID: AJCC Cancer Staging Manual. 6th edition. Springer-Verlag, Chicago, 2002.

23. Kim K, Lee KM, Han DJ, Yu E and Cho YM: Adult stem cell-like tubular cells reside in the corticomedullary junction of the kidney. Int J Clin Exp Pathol 1: 232-241, 2008.

24. Gupta PB, Chaffer CL and Weinberg RA: Cancer stem cells: mirage or reality? Nat Med 15: 1010-1012, 2009.

25. Tirino V, Camerlingo R, Franco R, et al: The role of CD133 in the identification and characterisation of tumour-initiating cells in non-small-cell lung cancer. Eur J Cardiothorac Surg 36: 446-453, 2009.

26. Rutella S, Bonanno G, Procoli A, et al: Cells with characteristics of cancer stem/progenitor cells express the CD133 antigen in human endometrial tumors. Clin Cancer Res 15: 4299-4311, 2009.

27. Yin AH, Miraglia S, Zanjani ED, et al: AC133, a novel marker for human hematopoietic stem and progenitor cells. Blood 90: 5002-5012, 1997.

28. O'Brien CA, Pollett A, Gallinger S and Dick JE: A human colon cancer cell capable of initiating tumour growth in immunodeficient mice. Nature 445: 106-110, 2007.

29. Ricci-Vitiani L, Lombardi DG, Pilozzi E, et al: Identification and expansion of human colon-cancer-initiating cells. Nature 445: 111-115, 2007.

30. Zeppernick F, Ahmadi R, Campos B, et al: Stem cell marker CD133 affects clinical outcome in glioma patients. Clin Cancer Res 14: 123-129, 2008.

31. Artells R, Moreno I, Diaz T, et al: Tumour CD133 mRNA expression and clinical outcome in surgically resected colorectal cancer patients. Eur J Cancer 46: 642-649, 2010.

32. Todaro M, Alea MP, Di Stefano AB, et al: Colon cancer stem cells dictate tumor growth and resist cell death by production of interleukin-4. Cell Stem Cell 1: 389-402, 2007.

33. Bao S, Wu Q, McLendon RE, et al: Glioma stem cells promote radioresistance by preferential activation of the DNA damage response. Nature 444: 756-760, 2006.

34. Woodward WA, Chen MS, Behbod F, Alfaro MP, Buchholz TA and Rosen JM: WNT/beta-catenin mediates radiation resistance of mouse mammary progenitor cells. Proc Natl Acad Sci USA 104: 618-623, 2007.

35. Chiou SH, Kao CL, Chen YW, et al: Identification of CD133-positive radioresistant cells in atypical teratoid/rhabdoid tumor. PLoS One 3: e2090, 2008.

36. Smith LM, Nesterova A, Ryan MC, et al: CD133/prominin-1 is a potential therapeutic target for antibody-drug conjugates in hepatocellular and gastric cancers. Br J Cancer 99: 100-109, 2008.

37. Ferrandina G, Martinelli E, Petrillo M, et al: CD133 antigen expression in ovarian cancer. BMC Cancer 9: 221, 2009

38. Piras F, Perra MT, Murtas D, et al: The stem cell marker nestin predicts poor prognosis in human melanoma. Oncol Rep 23: 17-24, 2010.

39. Bruno S, Bussolati B, Grange C, et al: $\mathrm{CD} 133^{+}$renal progenitor cells contribute to tumor angiogenesis. Am J Pathol 169: 2223-2235, 2006.

40. Corbeil D, Roper K, Hellwig A, et al: The human AC133 hematopoietic stem cell antigen is also expressed in epithelial cells and targeted to plasma membrane protrusions. J Biol Chem 275: 5512-5520, 2000.

41. Fargeas CA, Joester A, Missol-Kolka E, Hellwig A, Huttner WB and Corbeil D: Identification of novel Prominin-1/CD133 splice variants with alternative C-termini and their expression in epididymis and testis. J Cell Sci 117: 4301-4311, 2004.

42. Giebel B, Corbeil D, Beckmann J, et al: Segregation of lipid raft markers including CD133 in polarized human hematopoietic stem and progenitor cells. Blood 104: 2332-2338, 2004.

43. Weigmann A, Corbeil D, Hellwig A and Huttner WB: Prominin, a novel microvilli-specific polytopic membrane protein of the apical surface of epithelial cells, is targeted to plasmalemmal protrusions of non-epithelial cells. Proc Natl Acad Sci USA 94: 12425-12430, 1997.

44. Corbeil D, Roper K, Fargeas CA, Joester A and Huttner WB: Prominin: a story of cholesterol, plasma membrane protrusions and human pathology. Traffic 2: 82-91, 2001.

45. Rousseau A, Ayoubi F, Deveaux C, et al: Impact of age and gender interaction on circulating endothelial progenitor cells in healthy subjects. Fertil Steril 93: 843-846, 2010.

46. Lemieux C, Cloutier I and Tanguay JF: Menstrual cycle influences endothelial progenitor cell regulation: a link to gender differences in vascular protection? Int J Cardiol 136: 200-210, 2009. 